\title{
Algunas notas sobre el método de la economia y el método de la investigación económica
}

\section{Some notes on the method of the economy and the method of economic research}

\author{
Pablo Hermenegildo Rivas Santos ${ }^{1}$
}

\section{RESUMEN}

El presente artículo analiza cualitativamente el método que utiliza la economía (ciencia humana dedicada al estudio de las leyes universales que regulan la acción humana en un mundo donde prevalece la escasez de recursos y las necesidades humanas infinitas) para resolver los problemas económicos que le interesa a la sociedad; y por otro lado analiza cualitativamente el método que utiliza la economía para realizar investigaciones económicas ${ }^{2}$.

Palabras clave: Economía; leyes universales; escasez; necesidades humanas.

JEL: E, E 52

1 Universidad Nacional Mayor de San Marcos, Facultad de Ciencias Económicas. Lima, Perú. Profesor Asociado de Economía Monetaria e investigador del Instituto de Investigaciones Económicas E-mail: privass@unmsm.edu.pe

2 El presente artículo actualiza y revisa un método alternativo para estudiar la Economía y para hacer investigación económica de la segunda y séptima parte de "Principios de la Economía"; material de enseñanza presentado en Agosto del 2007 en la Facultad de Ciencias Económicas de la Universidad Nacional Mayor de San Marcos.

(C) Los autores. Este artículo es publicado por Pensamiento Crítico de la Facultad de Ciencias Económicas, Universidad Nacional Mayor de San Marcos. Este es un artículo de acceso abierto, distribuido bajo los términos de la licencia Creative Commons Atribucion - No Comercia_Compartir Igual 4.0 Internacional. (http://creativecommons.org/licenses/by-nc-sa/4.0/) que permite el uso no comercial, distribución y reproducción en cualquier medio, siempre que la obra original sea debidamente citada. 


\section{ABSTRACT}

This article qualitatively analyzes the Method that Economics uses (Human science dedicated to the study of universal laws that regulate Human Action in a world where scarcity of resources and infinite human needs prevails) to solve the economic problems that interest it. the society ; and on the other hand it qualitatively analyzes the Method that the economy uses to carry out economic research.

Keywords: Economy; universal laws; scarcity; human needs.

JEL: E, E 2

\section{Introducción}

La economía tiene por objetivo investigar los conocimientos a priori económicos, como los medios y fines, el momento oportuno, preferir y rechazar. Para comprender las teorías económicas, consideramos las particularidades del actuar de la gente. Mediante el análisis lógico del conocimiento de los conceptos a priori del actuar de la gente, se asimila las teorías económicas. Pensamos analíticamente sobre la constitución del actuar de la gente; en opinión de Von Hayek, F. (1974).

Las teorías económicas están implícitas en los priori económicos. Para conocerlos priori económicos analizamos y deducimos las teorías, extraemos sus conclusiones lógicas; y características del actuar de la gente. Una vez conocidos los requisitos del actuar de la gente; determinamos los requisitos específicos de las formas específicas del actuar de la gente formulando imaginariamente situaciones que resultan pensables; para deducir, las conclusiones lógicas. Tal sistemática ilustra: el actuar de la gente como acontece en la vida real, y el hipotético actuar de la gente que aparece en caso de concurrir las irrealizables condiciones de un mundo imaginario; en opinión de Von Mises, L.(1966).

\section{La metodología de la economía}

La economía analiza el actuar de la gente bajo supuestos y circunstancias de la vida real. Se aborda el actuar de la gente suponiendo circunstancias que no se han presentado; y que no se pueden presentar en el momento actual. Para ello, la Economía analiza planteamientos reales (que todavía 
no se presentan) y planteamientos irreales e irrealizables; sí este análisis permite comprender la realidad.

El conocimiento experimental nos dice: qué problemas conviene analizar (pero no nos dice cómo debemos analizar); y qué problemas no conviene analizar. El Pensar nos dice qué planteamientos imaginarios e impracticables conviene analizar para comprender la realidad.

En la vida real nos enfrentamos con el cansancio del trabajo. Sí se considera esta realidad; una teoría económica sirve para comprender lo que sucede a nuestro alrededor. Esta realidad ofrece datos experimentales, que (explicado a la luz del conocimiento apriori) permite que concluyamos lógicamente que la gente aprecia más el descanso que la labor (suponiendo fijo los demás acontecimientos):observamos personas que cuando trabajan más; abandona bienestares que podrían disfrutar; lo que hace que concluyamos lógicamente que hay personas dispuestas a renunciar determinados placeres renunciando el descanso. La vida real nos dice que la persona valora el reposo, mientras mira la labor como una sobrecarga. Así, concluimos lógicamente, porque acudimos primeramente al razonamiento económico; en opinión de Mundell, R.(1978).

La teoría del intercambio indirecto, donde el intercambio se realiza por medio del dinero, interesa para comprender la existencia verdadera y efectiva en un universo donde se practica el intercambio indirecto. En un universo en el cual solo se practica el intercambio directo, esa teoría sería un juego mental. No es posible que los economistas de ese mundo irreal estudiaran el intercambio indirecto. Pero, en el mundo real, el estudio del intercambio directo es un aspecto imprescindible del saber económico; en opinión de Rothbard, M.(1992).

El que la economía, al pretender conocer la realidad, sólo estudie los problemas importantes; no modifica la condición apriorística de su razonamiento económico. Así, se determina el campo de acción de la economía. La economía se plantea supuestos desligados de la realidad sí el análisis de esos supuestos permite comprender la realidad. En el estudio económico se combinan la ciencia económica; y el uso de sus teorías a específicos escenarios existentes y efectivos: la ciencia económica expresa sus enseñanzas combinando el saber apriori con el análisis e interpretación de lo real. Esta metodología es imprescindible; por la esencia y situación de los 
temas que toca la ciencia económica. Pero, usar este método exige prudencia y talento del economista.

Una teoría económica tiene importancia práctica sí en la existencia verdadera y efectiva existe el supuesto. Por ejemplo, la teoría del intercambio indirecto tiene importancia práctica sí en la realidad existe el intercambio indirecto. Así, una teoría económica es válida y exacta en el supuesto en el que participa la circunstancia prevista por esa teoría económica.

El conocimiento a priori del actuar de la gente, base de todo razonamiento económico, no admite crítica ni objeción: la gente trabaja para alcanzar ciertas metas que le atrae. La economía progresa en sus estudios mediante el razonamiento económico reflexivo. Todo conocimiento económico se adquiere mediante el razonamiento económico. La Economía precisando los supuestos y condiciones; estructura un sistema ordenado de ideas, deduciendo de ese sistema, mediante razonamiento lógicamente inatacable, las conclusiones lógicas que proceden. La Economía ante las conclusiones lógicas anuncia la seguridad y precisión de las aseveraciones en discusión o evidencia los excesos lógicos en que inciden las enunciadas cadenas deductivas.

La lógica es el instrumento utilizado para comprender las circunstancias que se encuentran dadas; la vida y la realidad son hechos dados. La lógica es la herramienta que dispone la gente para resolver la problemática que le plantea la vida real.

La comprensión no contradice las teorías económicas expresadas por la economía. La comprensión, ante determinado actuar humano: afirma las ideas que indujeron al hombre a actuar, las metas seguidas y los instrumentos utilizados para alcanzar las metas; y separa la correspondiente importancia de los elementos que participan en la manifestación de determinado suceso; sí las Disciplinas No Históricas (la Psicología, la Economía) son incapaces de resolver la duda.

El economista desea entender la vida real lo más cabalmente que le permiten la razón. El economista jamás podrá llegar a un pleno convencimiento: de que su investigación se halla acertadamente orientada; y de que son ciertas las verdades que considera incuestionables. El economista revisa con el máximo rigor el conjunto de sus tesis. Esto implica retroced- 
er todas las teorías económicas a los conocimientos a priori del actuar de la gente comprobando, mediante cuidadoso análisis, las sucesivas deducciones y conclusiones lógicas que finalmente consideran a la teoría; de que se trate. Tal metodología es la más efectiva para evadirla equivocación.

La Ciencia Económica es una disciplina deductiva. Su origen lógico viene de los conocimientos a priori del actuar de la gente de la cual parte en sus deducciones. Toda teoría económica que se aferre a la categoría de la acción humana, mediante una inatacable cadena racional, es admisible. Se aborda una rama económica sí esa rama ensambla perfectamente en la economía; en opinión de Roepcke, W.(1966).

El economista al estudiar cualquier tema debe considerar el conjunto ordenado del conocimiento económico; el economista no debe cultivar sólo una rama de la economía, sino otras ramas, como la historia económica, la política económica. Así, se analiza la realidad apoyándose en ideas preconcebidas, como los conocimientos a priori del actuar de la gente.

\section{La metodología para las investigaciones económicas}

La Economía analiza el origen de los precios que se observan entre los productos; la correlación de subordinación de los precios con el actuar de la gente; y la importancia de los precios con respecto al futuro actuar de la gente. El problema surge cuando el análisis obliga a abandonar el ámbito del mercado y de la oferta y demanda de mercado; ya que, para entender el mercado, se debe examinar el hipotético actuar de una persona aislada, y de un gobernante de un sistema socialista. Estudiar el cambio interpersonal, implica estudiar el canje intrapersonal y entonces, no es fácil trazar la línea divisoria entre qué actuar humano debe incluirse dentro del ámbito del mercado, y qué actuar humano debe excluirse ${ }^{3}$; en opinión de Reig, J. , Velasco, G. y Benegas Lynch, A.(1980).

El actuar de la gente lo impone la aspiración de eliminar cierto malestar. La materia de la ciencia económica es estudiar el precio de los productos; tal y como se desean y se abonan en el mercado. La gente bus-

3 Pues la Economía fue ampliando sus horizontes hasta convertirse en la Teoría General que abarca cualquier acción humana. Por eso es difícil determinar, dentro del campo de tal Teoría, los límites de la doctrina mercantil que solamente estudia los problemas económicos. 
ca productos por el beneficio que los productos le pueden dar. La gente quiere aumentar su bienestar mediante la satisfacción, que puede darle los bienes. En el campo de la economía se incluyen (entre las actuaciones económicas)aquellas actuaciones que directamente permite eliminar determinado malestar. Una orden médica, las clases de un docente, etc. caen dentro del campo de la economía; al igual que los mapas del ingeniero civil para construir una vivienda, la receta para obtener un bien físicoquímico.

La doctrina mercantil investiga el origen del mercado, su desarrollo, y sus efectos. La gente, en el mercado, busca productos de primera necesidad, vivienda, satisfacción y otros gustos inmateriales. A la gente le atrae, simultáneamente, bienes materiales y bienes no materiales. La gente elige entre diferentes opciones, despreocupándose de sí el bien que prefiere se considera, por otras personas, como bien tangible o intangible. En la serie de valoraciones todo se combina. Aun aceptando que sea factible trazar la línea divisoria entre unas y otras aspiraciones; el actuar de la gente: a veces desea alcanzar, simultáneamente, metas tangibles y no tangibles; y otras veces, elige productos de uno u otro tipo.

No hay comida que la gente aprecie tan sólo por su valor nutricional, ni vivienda, ni ropa que aprecie solamente por la protección que pueda darle contra la helada o la granizada. En el mercado de productos, intervienen motivos religiosos y éticos, juicios valorativos artísticos, propensiones, costumbres, obsesiones, modas y otras condiciones.

La Economía analiza los precios de los productos que se comercian en el mercado; y aborda el actuar del individuo aislado, del gobernante de una economía socialista y de la gente; de naturaleza económica; y no económica. La doctrina mercantil se ocupa del actuar que se ejerce basándose en el cálculo económico. El cambio de mercado y el cálculo económico están conectados. La llegada de la moneda y del cálculo económico está restringida por la existencia de la organización mercantil.

La ciencia económica estudia el funcionamiento del sistema económico estatista. Sin embargo, tal estudio, supone que previamente se estructura la doctrina mercantil, del procedimiento lógico que se basa en precios y cálculo monetario, ya que el sistema económico de mercado apareció antes del sistema económico socialista. 
La misión de la economía es resolver la problemática que se le aparece a la gente; porque mantener la vida de la gente requiere disponer de numerosos elementos tangibles. La función de la razón es enfrentarla problemática que le expone el ambiente natural; el potencial intelectual permite a la gente actuar frente a la escasez. La gente pensante y actuante surge en un universo donde hay escasez, donde el bienestar se conquista a través del trabajo, aplicando el comportamiento económico.

\subsection{La metodología de la investigación económica basada en modelos $^{4}$}

El economista que investiga problemas económicos usa el método basado en Modelos; donde los modelos deben formularse con la máxima prudencia y justeza examinando con un pensamiento crítico todos los supuestos y escenarios de los modelos.

Tal metodología reside en dejar de lado la acción concreta de algunas condiciones que intervienen en el modelo. Se permite mentalmente examinar el efecto que causaría excluir la acción concreta de esas condiciones; y darse cuenta el efecto de esas condiciones en caso de incluirlo.

Comprendemos el conocimiento a priori del actuar de la gente construyendo un modelo en que del actuar de la gente sería inadmisible porque la gente ya está totalmente satisfecha o porque la gente desconociera la manera que le permita aumentar su satisfacción; y el conocimiento a priori de la tasa de interés construyendo un modelo en que la persona no diferencia entre gozos que, durando igual período temporal, serían gozadas unas ahora y otras después; con relación al momento del actuar de la persona $\mathbf{5}$.

Un modelo es una construcción imaginaria de hechos resultados de una consecuencia lógica de precedentes acciones observadas; al exponer el modelo. Así, el modelo es resultado de la deducción, derivada del cono-

\footnotetext{
4 Tal método es realizado y perfeccionado en el marco de las investigaciones económicas.

5 Los modelos es la metodología que permite investigar temas económicos. Se trata de un método difícil de conducir ya que fácilmente induce al razonamiento falso. El economista que pretenda usar la construcción imaginaria está, caminando por resbaladizo borde, a cuyos lados están los precipicios lo ilógico y erróneo. Sólo una dura autocrítica evita caer en esos precipicios.
} 
cimiento a priori económico considerar y desconsiderar. El economista, cuando establece su modelo, no le interesa si muestra o no exactamente y obligatoriamente el mundo real que se propone analizar. No le importa averiguar si el modelo ideado existiría y funcionaría en la realidad. Ya que incluso modelos improcedentes, profundamente contradictorios y de imposible realización práctica, son útiles y hasta imprescindibles para entenderla realidad, sí es manejado con prudencia; en opinión de Von Hayek, F. (1976).

Los modelos que opera la ciencia económica no pueden confrontarse con la vida real. La función de los modelos es ayudar al investigador cuando emprende una investigación donde no puede acudir a la explicación sensitiva. Lo excepcional que exige el economista es confirmar sí las suposiciones del modelo concuerdan con las condiciones del actuar que se desea juzgar analíticamente.

\subsubsection{Economía de Mercado}

El modelo economía de mercado es la metodología que accede plantear los problemas económicos que interesa a la sociedad.

Supuestos del modelo economía de mercado:

i. Se ejerce la separación social de la labor.

ii. Se ejerce la pertenencia particular de los recursos productivos.

iii. Prevalece la compraventa de mercado de bienes y servicios.

iv. Ningún poder institucional perturba nada.

v. El gobierno estará dispuesto para resguardar el buen desenvolvimiento del sistema económico renunciando a actividades que puedan inutilizarlo; y resguardándolo contra posibles hostigamientos de terceros.

vi. Ninguna persona ajena al mercado obstruye tarifas, remuneraciones y tasas de interés; en opinión de Ravier, A.(2015).

La ciencia económica averigua qué consecuencias provoca este modelo. Expuesto las deducciones del análisis del modelo; se examina los prob- 
lemas que causa la interferencia estatal en la mecánica del mercado. Del análisis del modelo se obtienen conocimientos que permite comprender la realidad: el modelo al defender los salarios mínimos; describe, imaginariamente, las tácitamente insatisfactorias condiciones que registraría un mercado de trabajo libre; y el modelo al defender el control de precios, describe, los infelices efectos que provocaría un mercado no intervenido.

Para examinarlas medidas que limitan el libre juego de los componentes que constituyen un mercado libre, se examina las situaciones que genera la economía libre. Las metas que la gente lucha por conquistar a través del trabajo se logran; estableciendo un mercado de trabajo cuyo funcionamiento no se vea desequilibrado por la obstrucción gubernamental.

La independiente operación mercantil donde el cliente tiene la razón da buenos resultados.

El economista formula simultáneamente los modelos economía de mercado y economía estatista. En el procedimiento para descubrir el mecanismo de la economía de mercado; el modelo economía socialista goza de preferencia racional. Preocupa al economista el inconveniente de sí la ama de casase deleitaría de pollo y papas en la suposición de que no hubiera orden gubernamental que ordenara al granjero y al agricultora cumplir sus respectivas tareas. Rápidamente aparecería necesaria una participación del Estado para mandar a cada productor para que sirviera a sus compatriotas. Por eso, el economista se asombra al ver que esas órdenes coactivas no se necesitan. El economista al contrastar: la producción con la ganancia; la inversión privada con la inversión pública; el egoísmo con la generosidad; está usando tácitamente el modelo economía estatista. La sorpresa del economista(ante el "automático" ordenamiento del mercado)aparece cuando se da cuenta: de que a través de un "anárquico" sistema productivo cabe dar atención a las carencias de las personas de la manera más cumplida; que acudiendo a cualquier mandato que estructura un gobierno estatista.

\subsubsection{Maximizar beneficios}

El economista cuando se acerca a las dificultades que causa la economía de mercado, parte de la suposición imaginaria: las personas se afanan para conseguir las mayores satisfacciones personales. 
La ciencia económica al afrontarlas causas que provocan el actuar de la gente, afirma que la gente, mediante su actuar, procura eliminar sus malestares. Su actuar, en el ámbito mercantil, se concreta en la compraventa. El ofertante, en la disyuntiva de recibir más o recibir menos de un producto que vende; querrá (ceterisparibus) cobrar la máxima tarifa. Para el ofertante, cobrar el máximo precio supone una mayor complacencia de sus carencias. En cambio, la suma que el consumidor economiza al adquirirlo más barato le posibilita gastar una mayor suma en ambiciones que, en cualquier caso, hubieran quedado no satisfechas. Adquirir en el mercado más abaratado y ofrecer en el mercado más encarecido -suponiendo fijo las demás condiciones- es un comportamiento normal y obligatorio en toda compraventa.

El productor es un dependiente de los compradores, estando forzado a satisfacer los gustos de los compradores. Los gustos y preferencias de los compradores son regla suprema para el productor, sí solo sí el comprador pague el correspondiente precio. El productor adapta su actuación a la demanda de los clientes. El empresario producirá lo que los consumidores prefieran, aun contrariando sus propios gustos; cuando los consumidores son incapaces de valorar la belleza y prefieran productos rudimentarios y groseros. El empresario es forzado a proveerse de artículos extranjeros sí son más económicos que los artículos nacionales; sí el consumidor no está dispuesto a pagar más por artículos nacionales que por artículos extranjeros.

El productor no está permitido hacer benevolencia perjudicando a los clientes; no está permitido abonar sueldos mayores a los sueldos de mercado sí los clientes no están dispuestos a sufragar tarifas en mayor proporción por esos productos que han sido fabricado pagándole sueldos mayores.

Lo planteado es diferente cuando gasta su propia renta. En ese caso, el hombre procede como mejor le conviene. Si le agrada; le es posible donar y dar obsequios. Nada le detiene que seleccione contra productos de determinado origen; y prefiera adquirir productos que tecnológicamente son más malos o más costosos. Pero, lo natural es que el consumidor no beneficie de manera benevolente al productor; aunque a veces sucede. La línea divisoria que aparta la compraventa mercantil de productos; del obsequio caritativo, a veces, es difícil de delinear. La persona que hace com- 
pras en una reunión caritativa hace una combinación de una adquisición mercantil con un actuar caritativo. La persona queda unas monedas, en la avenida, a una cantante ciega, no está pagando por la precaria canción; está haciendo benevolencia.

La persona, al actuar, opera como persona individual: el productor dueño de una fábrica, puede anular la línea divisoria entre negocio y benevolencia. Si quiere ayudar a un compañero en aprieto, tal vez, por consideración, proponga alguna manera para evitar que ese compañero viva de la limosna. En este caso, puede darle un trabajo en su fábrica, a pesar de no necesitar ese trabajo o puede emplearlo a un reducido salario que el salario del mercado laboral. En tal alternativa, esa menor remuneración es un costo adicional del proceso fabril. Pero es gasto efectuado por el empresario de una porción de su ingreso. Esto es un desembolso de consumo. No un desembolso de la actividad productiva.

La predisposición a considerar sólo lo palpable, medible y visual (relegando el resto) nos lleva a cometer equivocaciones. El comprador no adquiere solamente proteínas o calorías. Desea alimentarse como una persona que razona. Existe multitud de personas que la comida le gusta más: cuando tiene buena presentación y sea más sabrosa, cuando está bien dispuesta en la mesa y cuando más atractivo sea el lugar. Estos sucesos no les interesan a quienes solo se fijan en las propiedades químicas de la evolución digestiva. El que esos sucesos tengan notoria consecuencia para determinar los precios de los alimentos no es incompatible con esa anterior aseveración; según el cual la gente prefiere adquirir en el mercado más barato. Cuando el consumidor en la elección entre 2bienes,que la física y la técnica suponen coincidentes, elige lo más caro; tiene sus razones para actuar así. A no ser que incida en equivocarse, al comportarse de esa forma, lo que está haciendo es remunerar por unos servicios que la física y la técnica (con sus metodologías específicas de investigación) no están capacitados para considerar. Tal vez, individualmente, consideramos extravagante la jactancia del consumidor que desembolsa por mayores precios asistiendo a un restaurante lujoso; solamente por tomarse la misma bebida al lado de un gran empresario y relacionarse con lo mejor de la sociedad. Lo que no está permitido es decir que tal consumidor no está optimizando su propio bienestar al actuar de esa manera. 
La persona procede para aumentar su satisfacción individual. Por esta razón cabe: usar la palabra egoísta; y afirmar que el actuar de la persona es egoísta. Incluso el actuar que directamente mejoran la condición ajena son de carácter egoísta, ya quela persona, individualmente, siente mayor bienestar al ver alimentarse a la gente que de alimentarse esa misma persona. Así, la Economía se interesa por el actuar del hombre, independientemente de que ese actuar sea causada por su apetito o por su aspiración de aliviar el apetito del prójimo.

Si, por maximizar utilidad, afirmamos que la persona, en la compraventa mercantil, desea aumentar lo mejor posible; su utilidad, incidimos, en exceso de palabras, ya que reiteramos lo que ya está incluido en el propio conocimiento a priori del actuar de la persona.

La ciencia económica no emite juicios de valor. La ciencia económica averigua los efectos que provocan determinados modos de actuar. La gente a través de sus juicios subjetivos de valor diferencia entre lo que le provoca más bienestar y lo que le provoca menos bienestar. Pero, el juicio de valor declarado por un individuo en relación al bienestar de una tercera persona nada dice del bienestar individual de esa tercera persona. Tal juicio de valor emitido afirma cuál es la situación en que, quien lo emite, quisiera ver a esa tercera persona; en opinión de Neira, A.Bagus, M.; y Rallo, J, Ramón, J.(2010).

\subsubsection{Economía Autárquica}

El economista para estudiar el cambio interpersonal, contrasta este cambio con suposiciones en que no ocurre esta variación. El economista acude a 2tipos del modelo economía autónoma: de la persona aislada que se autoabastece; y del gobernador de un país estatista. El economista, al valerse de este modelo, prescinde de la problemática de si la Economía autónoma funciona o no ${ }^{6}$.

6 El modelo es artificial. Ni a la persona individual ni a la autoridad de un sistema económico estatista les sería posible planear y realizar como si lo realizan quienes recurren al cálculo económico. pero, en el marco de ese Modelo; se supone que cabe hacer cálculo económico, si tal suposición posibilita estudiar mejor las problemáticas analizadas. 


\section{Supuesto}

La economía autárquica del gobernante de una sociedad socialista se basa en distinguir la actuación productiva de la actuación rentable; con fines de bienestar ${ }^{7}$. Se considera que la sociedad estatista, es el más anhelado y correcto sistema de gestión; se enjuicia los acontecimientos del sistema económico de mercado estudiando cada acontecimiento de acuerdo si el acontecimiento sea o no admitido desde la óptica una sociedad estatista. Se atribuye validez positiva a esas actuaciones que ejercería el gobernador de una sociedad socialista calificándolas de productivas.

El resto de actuaciones mejoradas en el sistema económico de mercado se califican de actuaciones inútiles independientemente de que beneficien a los que la ejercen. Por lo tanto, la técnica de ventas, el anuncio publicitario y la bancarización se consideran actuaciones con rentabilidad, pero improductivas ${ }^{8}$.

\subsubsection{Situación de Reposo}

\section{Supuesto}

Para estudiar el actuar de la gente se supone que el actuar tiende hacia un horizonte que alcanzado, impediría todo subsiguiente actuar: al eliminarse toda molestia; o al no haber posibilidad de ocultar en mayor grado la molestia que prevalece. Así, el actuar de la gente, de por sí, se orienta hacia la Situación de Reposo; a eliminar el actuar.

\section{Circunstancia}

La persona compra y vende artículos en el mercado hasta llegar el instante en que se detiene esa compraventa; al no existir ya nadie que crea que pueda mejorar su satisfacción a través de una siguiente compra venta. En esa circunstancia, a los virtuales consumidores no le interesarían los precios pedidos por los virtuales productores; y lo mismo ocurre a la inversa. Dejarán de comprar y vender los potenciales compradores y vendedores que, respectivamente, consideran el precio de mercado demasiado alto o demasiado bajo. Ningún intercambio se efectuaría. Así, surge la

7 Distinción en que se apoyan injustificados juicios valorativos.

8 Para la Economía no tiene importancia esos infundados juicio de valor. 
situación de reposo. Tal situación llamado situación natural de reposo, es una construcción imaginaria. Se presenta reiteradamente cuando cierra la Bolsa de Valores: los actores cumplen las órdenes que cabe cerrar, al actual precio de mercado. En cada momento se cierran compraventas que los concurrentes, a los actuales precios de mercado, están listos a admitir.

\section{Supuesto}

Se hacen nuevas transacciones; cuando valoraciones personales de los participantes.

Los teoremas que se incluyen en la situación natural de reposo son útiles y adaptables a todo tipo de compra venta: el empresario comprador de factores de producción, a la vista de la venta de su producto, se lanzará inmediatamente a producir, entrando, poco a poco, nuevamente al mercado con su producto, estimulado por la pretensión, a su vez, de adquirir lo que necesita; para su consumo y para seguir produciendo. Esto no anula la suposición "no suponer que perdure la situación natural de reposo": el reposo se desvanece apenas cambien esas transitorias situaciones que provocaron esa calma.

La situación natural de reposo describe lo ocurrido en el mercado: al analizar la situación natural de reposo, nos interesa lo que en este momento ocurre. Limitamos nuestro espacio hacia lo que transitoriamente ha ocurrido, omitiendo lo que más adelante ocurrirá en el siguiente momento (después); nos interesa aquellas tarifas que realmente se pagaron; en la correspondiente compraventa: nos importa las tarifas corrientes del pasado cercano.

\subsubsection{Situación Final de Reposo}

Interesa los factores perturbadores aptos para desencadenar una predisposición a la alteración de precios. Averiguamos hacia dónde conduce esa predisposición, en tanto se agote su fuerza propulsora, causando una nueva situación natural de reposo. Llamamos tarifa estática a la tarifa de esa nueva situación natural de reposo. A este precio estático lo llamamos precio final. Para evitar confusiones hablamos de precio final, para referirnos por consiguiente, a esa nueva situación natural de reposo: que llamamos situación final de reposo. 
Esta situación final de reposo es una construcción imaginaria; ya que nunca se alcanzará. Antes de llegar a ser una realidad esa situación final de reposo surgirán factores inquietantes. Pero no hay más salida que acudir a esa construcción imaginaria ya que el mercado, en todo instante, se orienta hacía cierta situación final de reposo. En cada momento siguiente aparecen situaciones que hacen que se altere el mercado. El mercado encaminado, en cada instante, hacia cierta situación final de Reposo, no se detiene.

La tarifa de mercado es un hecho real; es la tarifa ala que efectivamente se realizaron las compras y ventas. Pero, la tarifa final es una tarifa teórica. La tarifa de mercado es realidad verdadera, siendo, posible calcularlo con exactitud numérica en soles. Pero, el precio final solamente se concibe partiendo de necesarias situaciones para que aparezca ese precio final. Ese precio final no puede traducirse en valor numérico citado en soles ni en determinados volúmenes de otros bienes. No surge en el mercado.

El precio de mercado no coincide con el precio final; de la prevaleciente organización del mercado. La doctrina de mercado fallaría en su intento de dar solución a la problemática que causa el determinar los precios; sí abandona el análisis del precio final. Ya que en esa prevaleciente estructuración de mercado que genera el precio de mercado; ya están actuando las fuerza, mediante cambios sucesivos, que generaría el precio final y la situación final de reposo (de no surgir nuevas situaciones)en opinión de Duncan, R.(2013).

El análisis para determinar los precios: examina los transitorios precios de mercado y la situación natural de reposo; y supone que en el mercado operan elementos que provocan variaciones continuadas de los precios, guiando el mercado hacia diferente situación natural de reposo. Los cambios de las situaciones determinantes de los precios no provocan simultáneamente todas sus consecuencias. Debe pasar un lapso temporal para que su potencial se agote: desde que surge una nueva circunstancia hasta que el mercado se adapte a esa nueva circunstancia, pasa un período de tiempo; y durante ese período temporal, empiezan a actuar nuevas situaciones.

Al tocar las consecuencias de esa alteración de las situaciones que intervienen en el mercado; observamos situaciones continuamente encade- 
nadas, situaciones que (pieza tras pieza) van apareciendo con consecuencias escalonadas. Cuánto tiempo debe transcurrir de una circunstancia a otra circunstancia, no se puede predecir. Pero, entre una circunstancia y otra circunstancia, existe un lapso de tiempo; lapso que, a veces, es tan corto que es posible prescindir, en la realidad. Así, el modelo situación final de reposo es útil para ver el movimiento temporal de las situaciones en el mercado.

\subsubsection{Economía de Rotación Uniforme}

\section{Supuesto}

El modelo economía de rotación uniforme se distingue por eliminarse: el pasar del tiempo; y la variación de los acontecimientos de mercado. La oferta y la demanda no se alteran. Sólo se admiten alteraciones que no influyen en los precios; suponiendo que no varían las situaciones presentes. La economía de rotación uniforme es un modelo imaginario donde los precios de mercado son iguales a los precios finales. Los precios no cambian; existe completa estabilidad.

\section{Circunstancias}

En el mercado las idénticas compraventas, se repiten una y otra vez. Equivalente cantidades de recursos productivos llegan a los consumidores en forma de bienes finales que lo consumen. No varían las circunstancias del mercado. Hoy es igual que ayer y mañana será igual que hoy. La estructura está en permanente cambio, pero no modifica de apariencia.

La situación natural de reposo de la economía de rotación uniforme se altera permanentemente; pero, retorna inmediatamente tal y como se mostró por primera vez. No varían las circunstancias operantes, incluso aquellas circunstancias que causan esas perturbaciones periódicas de la situación natural de reposo. Así, los precios no varían; son estáticos -o sonde equilibrio estático-.

\section{Supuesto}

Este mundo imaginario es habitado por individuos que nacen, crecen y mueren sí no cambia el número total de habitantes ni la cantidad de personas que compone cada grupo de la misma edad. En esta suposición no 
varía la adquisición de productos cuya demanda se ejecuta solamente en ciertas épocas vitales, a pesar de que no sean los mismos individuos los que provoquen la oportuna demanda.

En la economía de rotación uniforme, se prescinde del tiempo y de la variación de los fenómenos del mercado. Pero, para estudiar los problemas que causa: la variación de las condiciones económicas y la variación discontinua y fluctuante del mercado; se necesita examinar estas variaciones con esa situación irreal, en la cual, supuestamente, estas variaciones se eliminan. Así, el modelo economía de rotación uniforme se utiliza para tocar este mundo inconstante 9 .

Esta metodología estática es la herramienta mental para examinarla variación. Para analizar los fenómenos complejos que causa el actuar de la gente, comenzamos examinando la ausencia de variación, para luego, incluir en el análisis; cierto factor capaz de causar específica variación, cuyo efecto examinamos; suponiendo constante las restantes circunstancias. Esta metodología estática es la metodología que toca la variación que interesa, careciendo de importancia, el que esa variación sea grande o pequeña, súbita o lenta.

El actuar de la gente es variación; y la variación supone sucesión temporal. Pero, en la economía de rotación uniforme se excluye: la variación y la continuación de las circunstancias. La actuación equivale a elegir, donde la personase enfrenta a la inseguridad del futuro. Pero, en la economía de rotación uniforme no se permite elegir, donde el futuro deja de ser incierto, ya que el mañana será igual al hoy que se conoce. En esta inalterable organización no aparecen personas que elijan y deseen y, tal vez, se equivoquen; al contrario estamos, frente a un universo de autómatas sin capacidad para meditar.

Sin embargo, tan inexplicables contradicciones no restan la ayuda que presta tal modelo sí se toca problemas para cuya respuesta; tal Modelo es conveniente y fundamental: el problema de relacionar precios de productos finales y precios de los insumos(necesarios para producir esos productos finales); y el problema que causa el actuar empresarialmente y las utilidades y pérdidas.

9 Por lo mismo, se recomienda a los economistas se interesen por lo "estático". 


\section{Supuestos.}

i. Para entender la actuación empresarial, y el significado de las pérdidas y ganancias, suponemos un sistema en que no se danesas realidades. Este supuesto no se puede llevar hasta sus últimos efectos lógicos; porque es absurdo excluir la actuación del empresario de la Economía de Mercado. Los distintos insumos no pueden mecánicamente agruparse para generar un producto final. Es necesario la participación razonada de una persona que aspira a conseguir determinados objetivos en la pretensión de mejorar su propia situación de bienestar. Anulado el hombre de empresa, se elimina el esfuerzo que moviliza el mercado.

ii. Este modelo padece de otra contradicción: en tal Modelo suponemos implícitamente que existe la moneda y el intercambio indirecto. ¿Qué tipo de moneda existe en este universo irreal? en opinión de Von Mises, L. (1966).Bajo tal Modelo donde no hay variación; se elimina la inseguridad en relación al futuro y por lo tanto nadie necesita tener dinero: como la gente sabe con exactitud, qué suma de dinero necesita, en cualquier momento futuro; la gente puede prestar todo su dinero, sí solo sí ese préstamo venza en la fecha en que esa gente necesitará su dinero.

El Banco, tampoco necesita tener reservas dinerarias, ya que las cantidades que a diario se retiran del banco coinciden con las cantidades que ingresan al Banco.

iii. Todas las transacciones se realizan mediante transferencias sin usar monedas. En este caso, la moneda, deja de usarse como medio de cambio; sería una moneda ideal e indeterminada unidad contable de carácter inexacto e indefinido. La interposición, entre demandante y ofertante, de esa clase de expresiones numéricas, no influye en lo esencial de la operación; esta moneda sería neutral en relación al actuar económico de las personas. Pero, un dinero neutral no tiene sentido y es inadmisible.

Bajo tal Modelo, el actuar de la gente; está ausente. El lugar que ocupa la acción consciente de la persona que razona deseosa de eliminar su insatisfacción se reemplaza por reacciones automáticas.

Con tan arbitrario modelo pretendemos darnos cuenta de la predisposición, propio en todo actuar humano, a establecer una economía de rotación uniforme; predisposición que no alcanzará el objetivo de instaurar 
esa economía de rotación uniforme mientras actuemos en un mundo que no es completamente tieso y no cambiable; en un mundo dinámico.

Darnos cuenta de la diferencia entre un universo dinámico, en el que hay acción, y un universo rígido; lo comprendemos a través del argumento opuesto, que nos ofrece la imagen de una economía estática. Este contraste nos ilustra: quehacer frente a las situaciones inciertas de un futuro inexplorado; es propio de la acción; que perder o ganar son instrumentos propios del actuar, imposible eliminar a través de inconsistencias de cualquier tipo.

\subsubsection{Economía Estacionaria}

En la economía estacionaria cabe que se produzcan variaciones: el volumen de la población aumenta o disminuye, sí paralelamente aumenta o disminuye la riqueza y el ingreso, según Von mises, 1966.

La variación de la demanda de capital; permite que el capital se transfiera del sector que debe contraerse hacia el sector que debe expandirse; mediante no renovar el capital del primer sector e instalar el capital en el segundo sector. Así, la Economía Estacionaria es una economía donde no se alteran el patrimonio ni el ingreso de las personas.

\subsubsection{Economía en Expansión y Economía en Contracción}

El modelo economía estacionaria conduce a2modelos más: la modelación de una economía expansiva y la modelación de una economía contractiva. En el primer modelo, el porcentaje per cápita del patrimonio, el ingreso y los habitantes se orientan hacia montos mayores; en el segundo modelo, tienden hacia montos reducidos.

En la economía estacionaria la sumatoria total de las utilidades y pérdidas es cero; en la economía expansiva la sumatoria de las utilidades es mayor a la sumatoria de las pérdidas; y en la economía en contracción la sumatoria de las utilidades es menor a la sumatoria de las pérdidas.

Esos 3modelos son imperfectos ya que considera que es posible medir la riqueza y el ingreso de la sociedad; pero esa medición es irrealizable e, inclusive, absurda; no cabe acudir a tal mediación para aproximarse a la realidad. 
Sí el economista historiador considera la economía de determinada época de estacionaria, expansiva o contractiva; ello no implica que haya medido las condiciones económicas; el historiador recurre a la compresión histórica para llegar a esa consideración.

\subsubsection{Integración de las Funciones de la Teoría del Mercado}

Cuando las personas (al tocar la problemática que causan sus acciones) hablan de empresarios, capitalistas, terratenientes, trabajadores o consumidores; se refieren a tipos ideales. Cuando los economistas hablan de empresarios, capitalistas, terratenientes ${ }^{\mathbf{1 0}}$, trabajadores o consumidores se refieren a conocimientos a priori. Los tipos ideales representan hechos históricos y los conocimientos a priori se refieren a funciones. Los empresarios, capitalistas, terratenientes, trabajadores o consumidores de la doctrina mercantil personifican funciones que se aprecian en el mercado ${ }^{\mathbf{1 1}}$.

Una persona no solo es consumidor, sino, también empresario, terrateniente, capitalista, trabajador: las funciones del consumidor, empresario, terrateniente, capitalista o trabajador también coinciden en una misma persona. La persona al actuar combina funciones. La historia pretende clasificar a las personas según los fines que cada persona busca y los medios a manejar para conseguir tales fines. La economía, al analizar el actuar de la gente en la economía de mercado, pretende determinar sus conocimientos a priori económicos y sus Funciones. Estamos frente a dos diferentes deseos. Su distinción se observa al estudiar el conocimiento ideal de empresario.

En la modelación economía de rotación uniforme no hay sitio para el actuar empresarial, ya que, en esa modelación, no hay alteración que afecte a las tarifas. Al hacer caso omiso de esa supuesta no alteración; entonces cualquier alteración de las circunstancias influirá en el actuar: ya que el actuar desea estructurar una futura situación, futuro, que, a veces, se contrae al inmediato e inaplazable momento, ese actuar se ve influida por toda alteración, erróneamente prevista, de las circunstancias del período comprendido entre el inicio del actuar y el momento final

10 Es decir, mineros-agricultores-ganaderos.

11 El que la gente y la historia manejen conceptos económicos, creando Tipos Ideales no oscurece el distinguir entre Tipos Ideales y Conceptos Económicos. 
del plazo que se intentaba considerar; plazo de provisión. Así, la consecuencia del actuar es incierto. Actuar involucra especular. Eso ocurre en la economía verdadera y funcionante.

En el modelo economía de rotación uniforme nadie es empresario ni especula; pero, en la economía real y funcional, quien actúa es empresario y especulador: aquella gente que cuida niños en una economía de mercado y que cuida personas en una economía estatista (aun cuando esos niños y esa gente no actúa ni especula) se ve inquietada por los efectos de las especulaciones de aquella misma gente que cuida niños y personas.

La ciencia económica, al hablar del empresario alude a una función específica. Esa función específica es total condición propia e inseparable del actuar y es practicada por toda persona que actúa. El materializar esa función específica en una figura ideal supone usar un procedimiento metodológico. La palabra empresario expresa a la persona actuante visto a la luz de la incertidumbre inseparable a todo actuar. Al utilizar la palabra empresario, cualquier acción está ubicada en el acontecer del tiempo, por lo cual implica especulación. Los capitalistas, terratenientes y trabajadores especulan. El consumidor especula, al pronosticar adelantadamente sus necesidades futuras. Se cometen equivocaciones en ese pronóstico del futuro.

Trasladando la modelación empresario puro hasta sus últimos resultados lógicos. El hombre de empresa puro no tiene capital; el capital que usa, para su quehacer empresarial, se lo presta el capitalista. El empresario puro, ante la ley; tiene recursos productivos que ha comprado con ese préstamo. Pero, no es dueño de nada, porque frente a su activo existe un pasivo en igual monto. Si tiene éxito en sus operaciones, será suyo esa ganancia; pero, si fracasa; la pérdida será soportada por el capitalista prestamista. El empresario puro es un empleado del capitalista, que especula, por cuenta de ese capitalista, apropiándose de la totalidad de las ganancias, sin responder por las pérdidas. Lo planteado no se modifica, aceptando que una porción del capital sea del empresario puro, que se circunscribía a tomar prestado el resto. Cualquiera que sean los términos acordados con su capitalista acreedor, ese capitalista acreedor soportará las quiebras ocurridas, por lo menos en aquel porcentaje que no sean cubiertas con los fondos propios del empresa- 
rio puro. Así, ese capitalista(prestamista)es empresario (especulador); corre el peligro de dilapidar su capital; no hay inversión que se considere completamente infalible.

El agricultor aislado que trabaja la tierra para atender las carencias de su familia, se ve inquietado por las variaciones que suceda en la fertilidad agrícola o en el conjunto de sus carencias. Pero, en la economía de mercado, ese agricultor se ve inquietado por las variaciones que modifican la importancia de su quehacer agrícola en lo referente al suministro del mercado. Por eso, ese agricultor será empresario.

El dueño de los recursos productivos no puede desligarse de lo incierto del futuro: invertir dinero o bienes en la actividad productiva, abastecerse para mañana, es acción empresarial.

El empleado nace siendo dueño de ciertas destrezas; sus destrezas son recursos productivos muy competentes para ciertos trabajos, menos competentes para otros trabajos e incompetentes para terceros trabajos. El empleado, en la circunstancia de que no haya nacido con la habilidad necesaria para hacer determinada labor, habiéndola obtenido, más tarde; en lo referente al tiempo y gastos que ha tenido que invertir en ese entrenamiento, está en la misma postura que cualquier capitalista. Ha realizado una inversión con la finalidad de obtener de la inversión el correspondiente ingreso.

Mientras el salario del empleado dependa del salario que el mercado está listo a pagar por su trabajo; el empleado será empresario. El precio del trabajo varía cuando varían las condiciones presentes; de igual manera en que también cambia el precio de los demás recursos productivos.

\subsubsection{Distribución Funcional}

El empresario actúa mirando las variaciones de las circunstancias del mercado. El capitalista y terrateniente actúan mirando las variaciones de valor y precio que (aun manteniendo fija las demás condiciones del mercado) ocurren con el paso del tiempo, a causa de la diferente valoración que poseen los productos presentes con respecto a los productos futuros. El empleado (como recurso productivo) usa su capacidad de trabajo, para obtener salarios. 
Así, se integran las funciones: el empresario recibe ganancias o pérdidas; los terratenientes o capitalistas(los dueños de factores de producción)reciben una tasa de interés; los empleados reciben sueldos. De esa manera, se estructura el modelo distribución funcional.

Pero, la ciencia económica usa la palabra empresario en sentido diferente al que se usa en el modelo distribución funcional. Para la ciencia económica, empresario es aquel individuo deseoso de obtener ganancia al adaptar la producción a las alteraciones del mercado sólo por él previsto; de mayor iniciativa, óptimo ánimo de aventura y mirada más aguda que la mayoría; atrevido e ingenioso que, siempre adelante, engendra el desarrollo de la economía.

Esta segunda noción de empresario: es menos completo que el concepto de empresario esgrimido en el modelo distribución funcional; no incluye supuestos incluidos por el modelo distribución funcional.

Usar una misma palabra para nombrar 2 Conceptos diferentes causa desorden. Mejor hubiese sido interponer otro término, para referirse a este segundo concepto de empresario; tal vez, cabría en este supuesto recurrir a la palabra promotor.

La noción de empresario-promotor no puede definirse con precisión teórica. En esto se parece a la noción de dinero, el cual no puede ser definido con precisión teórica -a diferencia de la noción de medio de cambio-. Pero, la ciencia económica no puede omitir al promotor, pues en el promotor representa una circunstancia genérica y característica de la naturaleza del hombre, que aparece en todo intercambio mercantil, condicionándola. Ello es así; porque los individuos, ante la variación de la coyuntura, no reaccionan con la misma velocidad, ni de la misma manera. La diferencia entre las distintas personas, diferencia generada por sus propias peculiaridades y por los sucesos de la vida, reaparece también en esta materia. En el mercado: hay personas que inician el camino; y hay personas que copian lo que hacen sus más habilidosos compatriotas. La aptitud de Mando causa sus consecuencias en el mercado y en cualquier otra condición del actuar humano. La potencia motriz del mercado, el empuje que genera la creación y el avance, proviene del Promotor, ansioso de aumentar su provecho personal. 
Siempre que haya imprecisión, cabe eliminar la imprecisión usando la palabra promotor en vez de la palabra empresario.

Mediante las compras y ventas a plazo; el especulador renuncia a una parte de su función empresarial. Pero, en la medida, en que (a través de esas compras y ventas a plazo) ese especulador se resguarda de posibles quiebras futuras, abandona su rol empresarial a favor del tercero que contrata con él.

Por ejemplo, el empresario constructor, al comprar fierro al contado, y paralelamente al venderlo a plazo, abandona una parte de su función empresarial. La variación del precio del fierro durante el tiempo en cuestión, no le afectará a ese empresario constructor en forma de pérdida o ganancia. Pero, ese empresario constructor no renuncia totalmente a la función empresarial; en cambio (pese a vender a plazo)le afectará todo cambio, que no se deba a ese cambio en el precio del fierro, registrada en el precio de las construcción es en general o delos específicos departamentos que él construye. Aun el empresario laborando a destajo y que (por cierto monto de dinero) tenga él de antemano vendida la correspondiente producción; seguirá procediendo como un hombre de empresa en lo referente al capital invertido en sus equipos productivos.

Admitimos una economía donde todos los productos se compran o venden a plazo. En esa economía, el rol empresarial se distingue y se separa de las otras funciones. Aparecería un tipo compuesto por empresarios puros. Los precios formados en los mercados a plazo regularían todas las producciones. Sólo las personas que intervinieran en esas producciones obtendrían utilidades o pérdidas. El resto de los habitantes estarían asegurada contra la inseguridad del futuro; gozarían de total despreocupación. Los presidentes de las firmas vendrían a ser empleados, con sueldos fijados anticipadamente.

Si además consideramos: que esa Economía; pertenece al modelo de economía Estacionaria; y que existe una empresa que hace la totalidad de las compras o ventas a plazo, entonces la totalidad de 
las pérdidas se igualaría a la totalidad de las utilidades. Sería suficiente con estatizar esa empresa para establecer un socialismo sin quiebras ni utilidades, una organización de indestructible seguridad y estabilidad. Por el contrario, bajo una economía activa, necesariamente habrá superávit de pérdidas o de ganancias.

\section{Conclusiones}

Se ha presentado el método de la Economía y el método de la investigación económica abordando conceptos manejados contra el sistema económico de mercado y que se usan como base para propuestas que se presentan para establecer un sistema económico intervencionista. El pensamiento intervencionista cobra lógico origen en el espacio de esos ficticios modelos en donde se materializa la economía de rotación uniforme o la economía estacionaria. El discurso con que los intervencionistas tocan esos imaginarios supuestos y las correspondientes estaciones de equilibrio hace que las personas no piensen que esas construcciones son objetos ideales, profundamente contradictorias, puros instrumentos del pensamiento, desprovistos, por sí mismos, de importancia práctica y que nunca servirían de modelo para constituir un planeta real, habitado por gente que actúa.

\section{Referencias Bibliográficas}

1. Alonso Neira, Miguel; Bagus, Philipp y Rallo Julián, Juan Ramón. (2010). "La crísis subprime a la luz de la teoría austriaca del ciclo económico:expansión crediticia, errores de decisión y riesgo moral”. España. Revista de Economía Mundial Volumen N 28. Pag. 145-171.

2. Duncan, Richard. (2013). “La nueva depresión”. España. Editorial Pearson. Pag. 17-32.

3. Mundell, Robert A.(1978)."EL HOMBRE y la ECONOMÍA”. Argentina. Editorial Amorrurtu.

4. Ravier Adrián, Osvaldo. 2015. "Repensando la macroeconomía del capital”.España.Pag. 5-37. Revista de Instituciones. Ideas y Mercado.

5. Reig, Joaquín; Velasco Gustavo y Alberto Benegas Lynch.(1980)“Deliberaciones sobre la libertad". México D.F. Editorial Centro de Estudios sobre la Libertad. 
6. Rivas Santos, Pablo Hermenegildo. (2007) "Principios de Economía” Perú. Facultad de Ciencias Económicas de la Universidad Nacional Mayor de San Marcos.

7. Ropcke, Wilhelm.(1967).“ECONOMÍA POLÍTICA”. España. Alianza Editorial.

8. Rothbard, Murray. N.(1992).“Moneda libre y controlada”. México D.F. Editorial Centro de Estudios sobre la Libertad.

9. Von Hayek, Friedrich. (1978). "Desnacionalización del dinero". España. Editorial Continental. Pag. 143-187.

10. Von Hayek, Friedrich. (1974). "Conferencia Nobel”. Suecia. Editorial Continental. Pag. 14-18.

11. Von hayek, Friedrich.(1979).“Precios y producción”. España. Alianza Editorial. Pag 170-199.

12. Von Mises, Ludwig.(1966)."Tratado de economía”.España. Editorial Fundación Ignacio Villalonga. 